would suffice for this and meanwhile satisfy some of the above needs from income.

(i) Sponsorship without financial commitment of appropriate conferences such as the projected series of International Conferences on Waste Minimization and Clean Technology.

Further projects are under consideration, including urgent research proposals, a major World Heritage Series of volumes, establishment of a biennial award for demonstrated environmental concern and concomitant action by a multinational corporation, and fostering the establishment of associated foundations etc. in other parts of the world. With the demise of the Pahlavi Prize, the modest value by modern standards of its successor the International Sasakawa Environment Prize, and the opening of the Tyler Prize to wider concerns, a major award for environmental leadership is an urgent need-if possible on a par with the Nobel Peace Prize (for which, incidentally, the nomination of leading environmentalists seems particularly desirable).

\section{Operation AND NeEDS}

With the running costs already largely accounted for, and in the absence of any institutional overheads and taxes other than those that continue to be paid privately, the
Foundation constitutes what has been called a uniquely economic vehicle for support of the environmental/conservational movement - whether generally or through specific projects which can be put in train as soon as or soon after funds become available. Contributions are warmly welcomed and individually acknowledged, and can be received in any negotiable currency by cheque made out to the Foundation for Environmental Conservation, c/o Banque Populaire Suisse, 1 Quai des Bergues, 1211 Geneva, Switzerland, or sent to the Foundation's address ending this notice. [Plans for recognizing special services or substantial donations to the Foundation by the award of an engraved certificate designed by a renowned draughtsman have been shelved with the death of the draughtsman and in view of the urgent need of all available funds for more pressing purposes, though donors are requiested to identify themselves clearly unless anonimity is desired.]

\section{Nicholas Polunin, President \\ The Foundation for Environmental Conservation (updated version following its 13th Annual General Meeting, held on 8 April 1988). \\ Address: 7 Chemin Taverney \\ 1218 Grand-Saconnex \\ Geneva, Switzerland.}

\title{
Repetition of Summer School for Multidisciplinary Assessment of Environmental Risks for Human Health
}

The 1987 event at the University of Siena, Italy, announced on p. 180 of the Summer issue of last year's Environmental Conservation, proved so successful that it is being repeated from the 17 th to 30 th of October this year.

Food, lodging, and travelling expenses, will be provided for 15 Italian students, and food, lodging, and part of their travelling expenses, for 15 foreign students. For direct acceptance for the course, a degree in Medicine or Biology from a recognized University is required, though holders of degrees in related fields may also be considered.
The official language of the Summer School will be English, and the expected deadline for applications will be 30 July 1988 . For further information please contact the undersigned (telephone 0577-288428):

ARisteo Renzoni, Professor \& Chairman Dipartimento di Biologia Ambientale Via delle Cerchia 3 53100 Siena, Italy.

\section{Risk Management and Rapid Urban Growth}

From 9-20 May* 1988, in Maastricht, the Netherlands, a two-weeks' course is on offer dealing with urban risk management. The course, designed for people of various occupations ranging from urban planners to industrial-plant managers, will provide a unique opportunity for participants to interact with others who share similar concerns but have varied backgrounds and fields of knowledge regarding and relating to urban risk management.

The course also provides unique opportunities for 'hands on' computer simulation work as well as several visits to sites in areas where environmental and urban planning coexists with industrial and urban expansione.g. the Environmental Control Room in the industrial heart of the Rotterdam harbour area, an oil refinery, and a chemical plant.

An international group of lecturers has been assembled for the course: from France, Canada (Professors Burton and White, of the Institute of Environmental Studies, University of Toronto), Germany (Professor Hafele, DirectorEd.
General of the Julich Nuclear Research Centre), various Dutch industrial corporations (representatives of Shell Petroleum Ltd, Dutch State Mines, and Gist-Brocades), and the Dutch Ministry for Housing, Physical Planning, and the Environment. By the end of the course the participants will have gained an understanding of the range of some of the new methods and approaches available, and knowledge of what questions to ask and which specialists may be needed in particular risk situations.

For further information and registration forms, please contact: Jacqueline Reason at IFIAS-Maastricht, Witmakersstraat 10, 6211 JB Maastricht, The Netherlands. Tel. 03143250465 , telex. 56493 ecdpm nl, telefax. 03143253636 .

Alexander Burton, Admin. Assistant International Federation of Institutes for Advanced Study (IFIAS)

Project Development Office

Witmakersstraat 10

$6211 \mathrm{JB}$ Maastricht

The Netherlands. 